\title{
Ds Dirk van der Hoff se bydrae tot die ontwikkeling van die Christelik-nasionale onderwysstelsel in die ZAR
}

\author{
E Oliver \\ Universiteit van Pretoria
}

\begin{abstract}
Reverend Dirk van der Hoff's contribution to the development of Christian National Education in the ZuidAfrikaansche Republiek

Today, Afrikaners are closely associated with the Christian National system of education. This system has a long and interesting history and many people have been involved in its development. This article shows the vital and essential role that Reverend Dirk van der Hoff, the first resident minister of religion in the ZAR, played in the structuring of CNE.
\end{abstract}

Wysigings aan onderwyswetgewing het die Christelik-nasionale lewens- en wêreldbeskouing wat deur die meerderheid van die Afrikanervolk aangehang word, onlangs weer in die kollig gebring.

Twee sake het na vore getree. In die eerste plek het dit duidelik geword dat die Christelik-nasionale onderwyssisteem diep gewortel is en as deel van die Afrikanervolkserfenis beskou word. Aan die ander kant het dit ook geblyk dat daar veral in Transvaal baie sterk aan hierdie beginsel vasgehou word. Die vraag ontstaan dan waaraan ons hierdie tendense te danke het.

In hierdie artikel sal gepoog word om baie kortliks die invloed wat die geskiedenis, en by name die werk van ds Dirk van der Hoff gehad het op die kweek en 
vorming van die Christelik-nasionale lewens- en wèreldbeskouing, soos dit neerslag gevind het in die onderwys in die ZAR, aan te toon.

\section{WORTELS}

Calvyn het onderwys en opvoeding gesien as 'n middel waardeur die geloof in God versterk en gebou moet word en die mens gebring moet word tot 'n Christelike lewe, om in gehoorsaamheid aan God en tot sy eer te lewe (Pont 1990:9). In 1860/1861 is 'n 'vereeniging voor Christelike Onderwys' in Nederland gestig.

Hierdie Calvinisties-georiënteerde opvatting oor onderwys wat in Nederland inslag gevind het, is ná die volksplanting na Suid-Afrika oorgedra (Schoeman 1991: 17), waar dit ontwikkel het en met die verloop van tyd ook omvorm is tot 'n Christelik-nasionale onderwysstelsel, in ooreenstemming met die Christelike leefwyse èn met die tradisies en ideale van die volk.

\section{ONDERWYS IN SUID-AFRIKA TOT 1853}

Hoewel onderwysgeleentheid aanvanklik maar min was en daar ook nie veel aandag aan geskenk is nie, is dit merkwaardig dat daar reeds onder die leiding van goewerneur Van Riebeek skakeling tussen onderwys en godsdiens was omdat die onderwys aan die sieketrooster opgedra is. Hierdie saamloop van godsdiens en onderwys is deur die goewerneurs voortgesit en loop uit op die ordonnansie van goewerneur De Cavonnes wat in 1714 as goewerneur in die Kaap aangestel is (Lugtenburg 1925:11). Die uitvoering van die inhoud van hierdie ordonnansie het by die kerk gelè. Die enigste toets waaraan kinders onderwerp is om te bepaal of hulle onderwys voltooi was, was of hulle as belydende lidmate tot die kerk toegelaat kon word. Geloofsbelydenis was ook 'n voorwaarde vir bevestiging in die huwelik. So het geloofsbelydenis die mondigheid van 'n persoon bepaal, op onderwysvlak, godsdienstige vlak en as staatsburger (Lugtenburg 1925:11). Hierdie ordonnansie het onderwys aan die Kaap vir die volgende 150 jaar bepaal. Die kerk het ook nougeset omgesien dat die minimum vereiste van geloofsbelydenis nagekom word. Afstande en afgesonderheid het tot gevolg gehad dat die mense aan die grense en buitewyke van die kolonie selfs hierdie minimum vereiste moeilik kon handhaaf.

Tydens die eerste Britse besetting is daar nie aandag gegee aan wetgewing met betrekking tot die onderwys nie.

In 1805 het goewerneur De Mist 'n omvattende ordonnansie in sake onderwys opgestel maar dit is nooit ten volle geïmplimenteer nie en ook nie ná die tweede Britse besetting voortgesit nie. 
Nadat verengelsing in 1822 die doel van onderwys geword het, het verhoudinge tussen die trekboere en grensboere en die staatsbeheerde onderwys versleg. Die boere het probeer om sover moontlik van rondgaande onderwysers gebruik te maak. Hierdie onderwysers (wat gewoonlik nie gekwalifiseerde onderwysers was nie) is veral gehuur wanneer een of meer kinders geloofsbelydenis moes aflê. Hulle is dan vir kort tydperke aangestel om die kinders te leer lees en skryf (Lugtenburg 1925: 13).

Staatsondersteunde skole is eers in 1839 aan die Kaap ingestel (Du Toit 1975: 57).

Die Trekkergemeenskappe het kort ná hulle vertrek uit die Kaap reeds op regeringsvlak aandag gegee aan die kwessie van onderwys: Die tweede Voortrekkergrondwet van Oktober 1838 het bepaal dat die owerheid 'n wakende oog oor die godsdiens en die skole moes hou. Van hierdie besluit het daar in die praktyk nie veel tereg gekom nie. Die onderwys het in 'n groot mate steeds op die skouers van ouers gerus. Hierdie opvoeding was ook beperk tot lees- en sangoefeninge en godsdiensonderwys (Lugtenburg 1925:21).

\section{Onderwys in Transvaal tot 1853}

Herhaaldelike pogings is aangewend on onderwysers vanuit Nederland en die Kaap te bekom, maar dit is eers in 1851 dat drie onderwysers uit Nederland na Transvaal gekom het. Professor Lauts het twee onderwysers gewerf om na Suid-Afrika te kom. Hendrik van der Linde (Lauts-versameling 402) en J W Spruyt (Lauts-versameling 417) se reisgeld is deur die Amsterdamse koopman Pijnappel voorgeskiet. Die Amsterdamse kommissie het ook daarin geslaag om 'n onderwyser te bekom, in die persoon van W J Poen. Sy reisgeld is volledig deur die Amsterdamse sinodale kommissie betaal. Hierdie drie onderwysers het aan boord van die Vasco da Gama na Suid-Afrika gekom. Die Volksraad het in Maart 1852 besluit om Van der Linde na Mooirivier (Potchefstroom) te stuur; Spruyt is na Rustenburg en Poen na Lydenburg gestuur.

Tot op hierdie stadium was onderwysers rondgaande en het die staat nie veel met die onderwys te doen gehad nie (Lugtenburg 1925:39). Nou was die Volksraad egter verantwoordelik vir die onderwysers wat hulle aangevra het en moes ook voorsien in die besoldiging en kontrolering van die onderwys. Dit was die eerste stap na staatskole. Tydens bogenoemde Volksraadsvergadering is daar ook 'n onderwysreglement goedgekeur wat deur Van der Linde opgestel is. Hierdie reglement het uit dertien artikels bestaan. Daarin word voorsiening gemaak vir skoolopsig deur die kerkraad. Artikel 5 het bepaal dat 'zijnde de onderwijzer verpligt aan alles een 
godsdienstige strekking te geven' (Volksraadsnotules 1852). Ouderlinge en diakens was verantwoordelik vir die salaris van die onderwyser. In hierdie eerste onderwyswetgewing is die kerklike opsig reeds duidelik sigbaar. Dit het die weg gebaan vir die latere ontwikkeling en uitbreiding wat ds Van der Hoff gebring het.

\section{VAN DER HOFF EN DIE ONDERWYS}

In Mei 1853 het ds Dirk van der Hoff as eerste predikant in die Oorvaalse aangekom. Tydens die reis na die ZAR het Van der Hoff beplan en besin oor die aard en omvang van sy werk. In 'n brief aan Lauts, skryf hy onder meer:

Hunne zedelijke en godsdienstige, benevens hunne verstandelijke ontwikkeling zal het hoofddoel van mijn streven zijn. Zie ik, dat het onderwijs niet voldoende is, dan begin ik met zelf een school op te rigten en zal dan zien of ik de Transvaalsche jeugd niet in zuiver hollandsch sprekende Afrikanen hervormen kan. Ontdek ik dat er nog aan meer onderwijzers behoefte is, en men wil mij magtigen om daarin te voorzien, ik zal alsdan zoo vrij zijn mijn tot u te wenden, op uwe bereidvaardigheid en goede keuze in dezen ten volle vertrouwende.

(Lauts-versameling 2/247)

As Nederlander wat gewoond was aan die Europese leefwyse, was Van der Hoff erg geskok oor die toestand waarin hy die onderwys aangetref het. Uit die eerste brief ná sy aankloms in die ZAR, gedateer 1 Augustus 1853 aan Lauts, blyk sy skok en verbasing oor hierdie toestand duidelik:

De onkunde onder het opkomende geslacht, dat is te zeggen tot den ouderdom van 40 jaar toe, is verregaande; natuurlijk met enkele uitzonderingen...schrijven of rekenen kunnen slechts weinigen, ja er zijn zelfs landdrosten en heemraden, die hun naam niet eens kunnen teekene. Wat het leezen aangaat, o! daar heeft men Jobs geduld voor noodig om het aan te hooren. $\mathrm{Zij}$ kunnen, ja, meest allen lezen, maar zóó, dat ze er bijna geen jota van begrijpen...het geheugen orgaan is voor $7 / 8$ toegesloten, het oordeel is verstompt, ja ik moet soms twijfelen of zij wel denken kunnen, tenminste in godsdienstige begrippen, wat hun wereldsche zaken aangaat, zegt men mij, gaat dat echter beter.

(Lauts-versameling 2/249)

Hierdie toestande het Van der Hoff gedring tot daadwerklike optrede. Sy eie geskooldheid en agtergrond het daartoe gelei dat hy 'n versiendheid geopenbaar het 
wat die Transvaalse burgers op daardie stadium nie van bewus was en nie verstaan het nie. Hy het naamlik besef dat hierdie volk se voortbestaan en ontwikkeling ernstig in gevaar gestel word deur hulle onkunde en gebrek aan onderwys en opleiding.

Ds Van der Hoff het dadelik begin om ondersoek in te stel na die stand van onderwys. Tydens die eerste kerkraadsvergadering is aan Van der Linde, die plaaslike onderwyser, ' $n$ onderhoud toegestaan. Deur bemiddeling van ds Van der Hoff is besluit om aan Van der Linde ' $n$ vasgestelde salaris te betaal wat deur intekenlyste van die ouers bekom sou word. Ds Van der Hoff het dit ook op hom geneem om met ouers te praat oor die noodsaaklikheid van onderwys en om kinders aan te moedig om die skole by te woon.

\section{Die 'Van der Hoff-reglement'}

Op voorstel van ds Van der Hoff is 'n nuwe onderwysreglement aanvaar, wat by somtyds ook as die 'Van der Hoff-reglement' bekendstaan (Lugtenburg 1925:47):

Artikel 1: Niemand zal zich hier te lande als onderwijzer der jeugd mogen vestigen, dan die daartoe behoorlijk geregtigd is, en van deze zijne bevoegdheid heeft doen blijken bij den Eerw. Kerkeraad, ter plaatse waar de leeraar gevestigd is.

Artikel 2: dat er voorlopig op elk dorp niet meer dan een onderwijzer zyn mag, daartoe door het Gouvernement aangesteld, in overeenstemming met den Kerkeraad.

Artikel 3: dat indien op een der dorpen men een kinderschool wil oprigten, dit geoorloofd zijn zal onder de volgende voorwaarden: i) geene andere kinderen in zulk eene school op te nemen dan die beneden de vijf jaren zijn; ii) de school te stellen onder opzigt der Kerkeraad; iii) zich niet te vestigen dan met toestemming van den Kerkeraad.

Artikel 4: dat als iemand als huisonderwijzer op de buitenplaatsen wenscht werkzaam te zijn hy zich zal moeten vervoegen by den Kerkeraad, waar de predikant is, en zich aan een behoorlijk onderzoek by den predikant zal moeten onderwerpen.

(Die term 'kerkraad' word in die reglement omskryf as die plek waar die leraar gevestig is. Om hierdie rede was die Potchefstroomse kerkraad in beheer van die onderwys oor die hele Transvaal.)

Hierdie reglement is aan die Volksraad voorgelê, waar dit op 21 November 1853 aangeneem is met die beperking dat artikel 3 nie op plaasskole van toepassing is nie. (Hier word die eerste onderskeid tussen plaasskole en dorpskole getref.) 
Die salarisreëlings van die kerkraad aan onderwysers is ook deur die Volksraad aanvaar. So gee ds Van der Hoff aan die kerk 'n aktiewe deel en beherende toesig oor onderwys en opleiding. Die kerk se taak as opvoeder word uitgebrei tot op die vlak van skoolonderrig en die staat sou nie by magte wees om onderwysers aan te stel sonder die goedkeuring van die kerk nie.

Tydens die Volksraadsvergadering word ds Van der Hoff aangestel as 'Binnenen Buitenlandsche Correspondent voor kerk- en schoolzaken' en as 'schoolopziener' te Potchefstroom (Volksraadsnotule 1853). Daardeur is Van der Hoff se invloed op onderwyssake bevestig en versterk.

Omdat ds Van der Hoff se gemeente die hele Transvaal beslaan het, het hy die geleentheid gehad om sy invloed in die onderwys ook buite Potchefstroom te laat geld en die strukture te hervorm. Tydens 'n besoek aan Lydenburg het die kerkraad op 13 Februarie 1854, onder sy leiding besluit om 'n vaste traktement aan Poen, die onderwyser, uit die kerkkas te betaal. Omdat die Amsterdamse Kommissie verantwoordelik was vir die uitstuur van Poen na die ZAR, het die Volksraad hier geen aandeel in die onderwys gehad nie. Poen het opgetree as 'godsdienstonderwyser en oefeninghouder' vir die Lydenburgers. In die grondwet wat in 1853 onder invloed van Bührman opgestel is, het artikel 16 vir Christelike onderwys voorsiening gemaak: 'De Volksraad is ook verpligt een opzigt te houden over de scholen. En zullen zij waakzaam moeten zijn dat overeenkomstig afdeling 15 alles wat strydig is met Gods Heilige Woord gemeden en niet toegelaten wordt.' Teen Oktober 1858 kon die kerkraad nie langer die onderwyser se salaris bekostig nie en het die skool 'n privaat-onderneming geword.

Van der Hoff is tydens sy besoek aan Zoutpansberg deur die kerkraad op 2 April 1854 gevra om 'n onderwyser te bekom, waarvan die salaris en vrye inwoning deur die kerkraad gewaarborg is. Die kerkgebou was, soos elders in die land, tegelyk ook die skoolgebou (Kerkraad van Potchefstroom se brief aan die Staatspresident en Sekretaris van die goewerment 4 April 1859).

Op Rustenburg het ds Van der Hoff ook die saak rondom die onderwys behandel en 'n vaste salaris vir die onderwyser is gewaarborg.

Binne die bestek van ' $n$ jaar het ds Van der Hoff die onderwys in die ZAR as ' $n$ tydelike noodmaatreël onder die toesig van die kerk gebring. Die staat het die onderwys verwaarloos en staatsbemoeiing en -kontrole was net letters in die wetboeke. Die volk het dit aanvaar en die feit dat die kerk in beheer van die skool was het gemoedsrus gegee aan die wyfelende gemoedere wat nog letsels van die tyd in die Kaap gedra het, waar staatbemoeiing gelei het tot verengelsing. Onderwys het openlik onder invloed van die Christelike geloof gestaan. En die kontrole van kerklike kant oor die aanstelling van onderwysers het verseker dat die onderwys volkseie 
gebly het. Dit wat Van der Hoff hier vermag het, het die basis geword vir latere ontwikkelinge op die gebied van onderwys in die Transvaal.

\section{Terugslae}

Die groei van die onderwys is ongelukkig geknou deur verskeie faktore. Tydens die oggend van 14 Junie 1854 is 'n Algemene Kerkvergadering te Rustenburg gehou om Smellekamp se voorstelle in verband met die beroep van nog skoolmeesters en predikante te bespreek. Hy is deur ds Van der Hoff teëgestaan omdat Van der Hoff se reisgeld en traktement nog nie in orde gebring was nie. Hierop het 'n geskil tussen die twee manne ontstaan waarin Smellekamp deur die Lydenburgers ondersteun is. Die ongelukige uiteinde van die saak was dat Smellekamp verban is en die Lydenburgse kerkraad hom afgeskei hel van die res van die kerk. Hierdie voorval het ook 'n nasleep in die onderwys gehad. Van der Linde het uit sy pos bedank nadat hy hom by Smellekamp geskaar het en geweier het om voor die kerkraad te verskyn toe dié hom tot verantwoording geroep het omdat hy nie die eredienste bygewoon het nie. Ook Spruyt wat onderwyser op Rustenburg was, moes inderhaas die land verlaat nadat hy teen ds Van der Hoff kant gekies het. Onderwys kon nie voortgaan sonder onderwysers nie. Die skole is gesluit. Ds Van der Hoff het sonder sukses probeer om onderwysers uit Nederland te bekom.

'n Verdere ontwikkeling wat die voortgang van die onderwys ernstig geknou het, was die beperking op ds Van der Hoff se bewegings. Hoewel hy deur die Volksraad beroep is en hulle aanvanklik sy traktement beloof het, is hy nie deur hulle betaal nie. Die kerkraad van Mooirivier en vier ander mense het onderneem om sy traktement te waarborg op voorwaarde dat hy voortaan in Mooirivier sou bly (De ZuidAfrikaan 30 November 1854). Dit het 'n einde gebring aan ds Van der Hoff se invloed en betrokkenheid op die gebied van die onderwys in die res van die ZAR.

Die verdeeldheid op politieke en kerklike gebied het ook negatief op die onderwys ingewerk.

Hoewel ds Van der Hoff die skole in Potchefstroom en Rustenburg weer teen die begin van 1855 aan die gang gehad het, het hulle teen die begin van 1857 doodgeloop. Alles het stilgestaan op die gebied van die onderwys omdat daar geen onderwysers was nie.

Teen die middel van 1857 het die staat ingegryp en Scheurkogel as onderwyser aangestel. Die regering het ook die skoolgebou voorsien en sy salaris betaal. Die kerkraad moes hom eksamineer en besluit of hy bekwaam is (Lugtenburg 1925:54). Na drie maande is Scheurkogel egter uit sy pos ontslaan omdat sy dissiplinére maatreëls te straf was. 
Nadat vorige pogings misluk het, word 'n finale grondwet in 1858 aangeneem. Artikel 24 hiervan bepaal die volgende: 'Het volk verlangt de opbouw, bloei en welvaart van kerk en staat en uit dien hoofde voorziening in de behoefte van Nederduitsch Hervormde Predikanten en Schoolmeesters.'

Die staat het nou meer belangstelling in die reëling van onderwyssake getoon. Op 7 April 1859 is Van der Linde weer as goewerments-onderwyser aangestel. Die skool op Potchefstroom is heropen en daar is ook 'n plaaslike skoolkommissie benoem (St Crt der ZAR Vol II, 21 Mei 1859). Van der Hoff en Pretorius het albei op hierdie vyfman-kommissie gedien. Die kommissie het opdrag gekry om 'n nuwe reglement vir onderwys op te stel. Op 19 April 1859 is die gevraagde reglement ingelewer wat vir etlike jare die onderwys in die Republiek sou bepaal. In hierdie reglement, wat uit 'n dertigtal artikels bestaan, word die kerklike aspek en die leerinhoud bepaal. Die inhoud en metode van onderwys is omskryf. Selfs die kerklike lidmaatskap van die staatsonderwysers is wetlik bepaal. Hoewel daar geen oorblyfsels van die Van der Hoff-reglement hierin te bespeur is nie en die offisiële mag wat die kerk oor onderwys gehad het weggeneem is, was die invloed van ds Van der Hoff tog duidelik sigbaar. Die Christelike beginsels en volkseie aard van die onderwys was teen hierdie tyd 'n goed-gevestigde feit. In die staatskoerant van 22 April en die daaropvolgende dae verskyn stukke van Veritas waarin ouers aangemoedig word om hierdie onderwysgeleentheid vir hulle kinders aan te gryp. Hy waarsku ook teen laksheid en die slagspreuk van die tyd wat vooruitgang strem: 'Mijn vader wist niets meer dan ik, en hij is wel door de wêreld gekomen, waarom moet mijn kind of mijne kinderen meer dan ik kennen?' Ook word Van der Linde gemaan om hom te weer hou van kerklike en staatkundige redetwiste.

$\mathrm{Na}$ byna drie jaar se gesukkel is daar uiteindelik in 1858 'n onderwyser aan Pretoria voorsien. Hy was die Nederlander Hendrik Stiemens.

\section{Die Algemene Skoolkommissie}

Die 1859-reglement

Op 5 Mei 1859 benoem die Volksraad 'n Algemene Skoolkommissie vir onderwys wat as die eerste effektiewe onderwysadministrasie in Transvaal tot 1867 gefunksioneer het. Van der Hoff het ook as lid van hierdie kommissie gedien. Die taak van hierdie kommissie was om toesig te hou oor die onderwys in die hele republiek. Dit het as sodaning bly funksioneer tot 1867. Hoewel dit hieruit mag lyk of ds Van der Hoff se invloed só weer verbreed word, was dit nie die geval nie.

Van die lede van die Kommissie het die gewelddadige onderbreking in die onderwys in 1854 en die monopolie wat die kerkraad en ds Van der Hoff in die onder- 
wys verkry het deur die 'Van der Hoff-reglement', sterk afgekeur. Hulle het die idee dat die kontrole oor onderwys by die staat lê, sterk op die voorgrond gedruk (Lugtenburg 1925:63). Die 'Van der Hoff-reglement' is in sy geheel uitgelaat en die reglement van Van der Linde is as raamwerk vir die nuwe reglement gebruik:

- Artikel 1 handel oor die salaris van die onderwyser, vrye inwoning, skoolgelde en skoolgebou;

- artikel 3 bepaal dat behoeftige kinders gratis onderwys sou ontvang;

* in artikel 8 word die vakke wat aangebied word uitgestip: '[S]chryven, rekenen, getal en vormleer, taal- en aardrykskunde, vaderlandsche, algemene en bybelsche geschiedenis, het zingen van psalmen en gezangen, bij die Nederduitse Gereformeerde Kerk in gebruik, terwyl tevens ook in de zangkunde onderwys zal gegeven worden;'

- artikel 23 stel dat die onderwyser 'n goewermentsamptenaar is;

- artikel 25 verplig die onderwyser om 'n 'ondermeester' aan te stel wat die onderwyser self moes besoldig.

- artikel 26 bepaal dat die onderwysers lede moes wees van die Nederduitse Gereformeerde Kerk en dat hulle bewyse van bekwaamheid en bevoegdheid aan die skoolkommissie moes vertoon. Die Algemene skoolkommissie het ook die onderwysers geëksamineer en sertifikate van bevoegdheid uitgereik.

Hier is dus 'n onderwyswet waarin die staat die inisiatief geneem het en die staatskool begin vorm aanneem. Dit gebeur in 1859, sewentien jaar ná die stigting van Potchefstroom en ses jaar nadat ds Van der Hoff hom in die ZAR kom vestig het.

Kort hierna is die onderwys opnuut in chaos gedompel deur die burgeroorlog. In Potchefstroom was die skool dán oop, dán toe (Lugtenburg 1925:70) en in die res van die land het dit nie beter gegaan nie. Gelukkig het daar ná 1863 'n herlewing gekom. Die kerk se invloed was beperk tot die toesien dat ouers hulle kinders laat leer - 'n saak wat baie aandag geniet het (Lugtenburg 1925:72). Oral waar onderwysers beskikbaar was, is skole heropen.

\section{Die 1866-Reglement}

Die 1859-reglement is deur die Algemene Skoolkommissie se reglement in 1866 vervang as nuwe onderwyswet vir die Republiek. Dit is 'n uitgebreide reglement met 64 artikels wat in vier dele verdeel is.

Die lede van die Algemene Skoolkommissie moes lidmate van 'n Protestantse kerk wees. Ook die onderwysers moes lidmate van 'n Protestantse kerk wees en hulle was verplig om onderrig te gee in Bybelse geskiedenis. Buite-onderwys staan regsteeks onder die veldkornet en die meesters moes ook kerklike hulp aan die 
veldkornet bied. Vir die eerste keer word daar voorsiening gemaak vir onderrig in Engels. Uit 'n verslag van die plaaslike skoolkommissie van Potchefstroom (Stauts Coerant VIII 131, 9 Januarie 1866) blyk dit dat ds Van der Hoff sterk ten gunste was van die Engelse onderrig naas Hollands.

Hierdie reglement het op 22 Februarie 1866 in werking getree, maar reeds in 1867 moes die konsep gewysig word omdat ds Van der Hoff as lid van die Algemene Skoolkommissie bedank het. In 1868 is die Algemene Skoolkommissie ontbind en die onderwys kom direk onder die sorg van die Uitvoerende Komitee. Dit was 'n draaipunt in die geskiedenis van die onderwys. Die Christelike en nasionale gees wat so volledig deel was van die onderwysstelsel is oorboord gegooi.

\section{ONDERWYS IN STAATSHANDE}

Hier word net baie kortliks gewys op die pad wat die onderwys in die volgende paar jaar geloop het om die rigtingverandering te teken.

Op 4 November 1874 word president T F Burgers se onderwyswet aanvaar. Die afwesigheid van ds Van der Hoff se invloed is duidelik sigbaar. Hierdie wet is in sy geheel geskoei op die Nederlandse basis. As inleiding is artikel 194 van die Nederlandse grondwet gekopieër (Wypkema 1939:329). In die inleiding word bepaal dat onderwys sover moontlik vry moet wees en word voorsiening gemaak vir eerbiediging van verskillende godsdienstige opvattings.

Dit was die eerste volledig wetlik bepaalde ondenwys in die ZAR en die begin van staatsondersteunde onderwys in Transvaal. Die bevolking was egter bitter ontevrede hiermee. Artikel 26, wat bepaal het dat godsdiensonderwys buite skoolure gedoen moet word, het groot ontevredenheid ontlok. Ook die nasionalisme, wat tot dusver byna ongemerk as vanselfsprekend hand aan hand met die Christelike onderbou gegroei en ontwikkel het, het hierdeur skade gelei. Die mense was van mening dat die wet té Engels en té Hollands was. Hierdie wet het eers op 16 Februarie 1876 in werking getree ná die aanstelling van W J van Gorkum as superintendent, en sy lewensduur was baie kort aangesien Transvaal in April 1877 deur Brittanje geannekseer is.

J V Lyle het Van Gorkum opgevolg. Die eerste gepubliseerde verslag oor onderwys verskyn op 7 Januarie 1879 (Transvaalse Gouvemements Courant 7 November 1879). Hierin word gewys op die ontevredenheid wat geheers het oor die gebrek aan godsdiensonderwys aan die een kant en ook die teenkanting teen vrysinnige' Nederlandse onderwysers wat tydens Burgers se regering ingevoer is, aan die ander kant. Burgers self was 'n aanhanger van die modernisme en hy wou hierdie ideologie versprei deur geesgenote as onderwysers en predikante te werf. Die kon- 
serwatiewe Afrikanernasie was egter nie hiervoor te vinde nie. So sterk was die teenkanting teen die president se verontagsaming van die volkseie dat sommige burgers tot trek gedryf is (De Volkstem 12 September 1873). Hoewel Lyle die onderwysstelsel as 'n staatsinstelling benader, het hy tog die aanvoeling gehad om te sien waar ernstige tekorte was. Hy het onder meer voorgestel dat die onderwys by die mense aangepas word en dat hulle godsdienssin erken word. Daarom moes daar een uit elk van die daaglikse vyf ure onderwys aan godsdiens afgestaan word. 'n Ander belangrike insig was die noodsaaklikheid van rondtrekkende onderwysers om sodoende by die praktyk aan te pas en soveel moontlik mense te bereik. Sy voorstelle is uitgevoer, maar hy sterf kort hierna en word opgevolg deur ds $\mathrm{H} \mathrm{S}$ Bosman as waarnemende superintendent. Hoewel nuwe wetgewing beoog is, bly dit agterweë omdat die Republiek in 1881 herstel is.

Gedagtig aan die probleme met die Burgers-wetgewing, word ds S J du Toit, wat bekend was daarvoor dat hy Christelik-nasionale onderwys in die Kaap bepleit het, na Transvaal genooi. Hy was 'n voorstaander van onderwys eie aan die Boerevolk. Teen die einde van 1881 lê hy sy hoofbeginsels rakende onderwys aan die owerhede voor en aanvaar sy amp as superintendent van onderwys op 13 Maart 1882.

Die hoofbeginsel van die Christeliknasionale onderwys is dat onderwys nie 'n saak van die staat is nie, maar wel van die ouers en die kerk. Die staat moet sy bydrae beperk tot ondersteuning en toesig oor die gebruik van geld. Hierdie wet is op 18 Mei 1882 aanvaar.

Hiermee was die stryd egter nie gewen nie, inteendeel, dit het in werklikheid eers begin. Die Christelik-nasionale onderwys het later in twee strome verdeel: Aan die een kant was daar 'n groep wat gelyke regte aan beide Nederlands en Engels wou gee en aan die ander kant die groep wat aan Nederlands voorkeur gegee het en waarby die Nederduitsch Hervormde Kerk hom geskaar het (Botha 1987:70). Daar was nog ' $n$ lang en moeilike pad voor na die Onderwyswetgewing van 1967 en manne soos ds M J Goddelroy en prof C H Rautenbach het die Hervormde standpunt deur die jare lewendig gehou (Botha 1987:57).

\section{SLO'T}

Die Nederduitsch Hervormde Kerk se standpunt oor Christelik-nasionale onderwys is nie uit die lug gegryp om omstandighede en politieke oortuigings te onderskryf nie. Dit is ' $n$ standpunt waarvan die geskiedenis terugloop tot by die invloed van Calvyn en 'n erfenis van die Nederlandse voorvaders. In die ZAR het ds Dirk van der Hoff hom as eerste predikant die taak opgelê om die onderwys onder die vleuels 
van die kerk te neem en in die rigting van ' $n$ Christelike en nasionale aard te stuur. Ten spyte van terugslae was sy werk nie vergeefs nie en het hy help bou aan die fondasie wat gegroei het tot die Christelik-nasionale onderwysbeleid wat vandag weer in die weegskaal lê.

Ek dra graag hierdie artikel in beskeidenheid op aan prof dr A D Pont, wat my geleer het dat kerkgeskiedenis nie feite uit die verlede is nie, maar ' $n$ verantwoorde lewe in die hede en 'n vertroude rigsnoer vir die toekoms. Ten opsigte van sy kennis, insig en interpretasie van gebeure het prof Pont min gelykes. Vir die studente sal sy weggaan 'n tragiese verlies wees. Die Fakulteit sal leeg wees sonder hom....

\section{Literatuurverwysings}

Botha, S J 1987. Ds M J Goddefroy en Christelik-nasionale onderwys. HTS 43, 57 70.

De Volkstem 12 September 1873.

De Zuid-Afrikaan 30 November 1854.

Du Toit, P S 1975. Onderwys in Kaapland, in Coetzee, J C (red), Ondenys in SuidAfrika 1652-1960. Pretoria: Van Schaik.

Kerkraad van Potchefstroom 1859. Brief aan Staatspresident en sekretaris van die goewerment. 4 April 1859.

Lauts-versameling A 13, 2/247;2/249.

Lugtenburg, A H 1925. Geskiedenis van die onderwys in die SA Republiek (18361900). Pretoria: Van Schaik.

Pont A D 1990. Onderwys en opvoeding by Calvyn. Konteks 1/5 bladsy 9.

Schoeman, S 1991. Ons pad vorentoe met Christelik-nasionale onderwys. Konteks 2/1 bladsy 17-18.

Staats Courant der ZAR 1859. Vol Il, 2 Mei 1859. Pretoria: Staatsargief.

-- 1866. Vol VIII 131, 9 Januarie 1866. Pretoria: Staatsargief.

Transvaalse Coevemements Courant 7 November 1879. Pretoria: Staatsargief.

Volksraadsnotules 1852, 1853. Pretoria: Staatsargief.

Wypkema, A 1939. De invloed van Nederland op de ontstaan en ontwikkeling van de staatsinstellingen der ZAR tot 1881. Pretoria: De Bussy. 